\title{
Forgetting of Intentions in Demanding Situations Is Rapid
}

\author{
Gilles O. Einstein \\ Furman University
}

\author{
Carrie L. Williford and Jason L. Pagan \\ Furman University
}

\author{
Mark A. McDaniel \\ University of New Mexico
}

\author{
R. Key Dismukes \\ National Aeronautics and Space Administration \\ Ames Research Center
}

\begin{abstract}
Demanding work settings often require the deferral of intended actions. In 3 experiments, participants were to withhold a response until they encountered a task change (which occurred 5, 15, or $40 \mathrm{~s}$ later). To approximate highly demanding settings, the experimenters sometimes divided attention during the delay period. During some of the delays the experimenters interrupted the participants with an additional task (Experiment 1). Demanding conditions as well as interruptions revealed rapid forgetting of intentions at levels that would be considered significant in applied settings. Experiments 2 and 3 showed that this rapid forgetting was not reduced by strategic rehearsal and implementation intention strategies. The results suggest that maintaining intentions over brief delays is not a trivial task for the human cognitive system.
\end{abstract}

A frequent real-world demand is remembering to perform an intended action over some delay. This type of memory task has been termed prospective memory and has received increasing attention in the basic literature. As Einstein and McDaniel (1990, 1996; McDaniel \& Einstein, 2000; McDaniel, Robinson-Riegler, \& Einstein, 1998) have noted, a critical difference between this type of memory task and retrospective memory tasks (e.g., cued recall) is that there is no external agent that requests a memory search when the target event occurs. To capture this critical aspect of prospective memory, the typical laboratory paradigm requires participants to perform an action whenever a particular event occurs in the context of a primary ongoing activity. For example, at the beginning of an experiment, participants might be asked to remember to press a designated key on the keyboard whenever they encounter a particular target word while performing a pleasantness rating task (e.g., Einstein, Smith, McDaniel, \& Shaw, 1997).

Whereas this paradigm captures some aspects of real-world prospective memory situations (e.g., remembering to stop at the

Gilles O. Einstein, Carrie L. Williford, and Jason L. Pagan, Department of Psychology, Furman University; Mark A. McDaniel, Department of Psychology, University of New Mexico; R. Key Dismukes, Human Factors Research and Technology, National Aeronautics and Space Administration Ames Research Center.

This project was supported by National Aeronautics and Space Administration Grant NCC-2-1085. These data were reported at the 41st Annual Psychonomic Society Meeting, New Orleans, Louisiana, November, 2000. We thank Lindsey Hancock and Sara Mayfield for their help in collecting data and Erica Rall for her help with data tabulation. We also thank Harold Delaney for graciously developing a program to compute the power analyses for the within-subjects effects.

Correspondence concerning this article should be addressed to Gilles Einstein, Department of Psychology, Furman University, Greenville, South Carolina 29613. E-mail: gil.einstein@furman.edu grocery store), it does not capture other prospective memory demands that occur. It is important to note that in natural settings one often thinks of an intended action but cannot perform it immediately because of the constraints of the current task. In these situations, execution of the intended action must be briefly delayed until the conditions for performing it are appropriate. This type of prospective memory challenge is also prominent in demanding work settings. For example, delays and disruptions of normal procedures are frequent in aviation operations (Dismukes, Young, \& Sumwalt, 1998; Loukopoulos, Dismukes, \& Barshi, 2001; Nowinski, Holbrook, \& Dismukes, in press). In their analysis of air traffic control settings, Vortac, Edwards, and Manning (1995) argued that delaying actions is common, sometimes because the action is not appropriate in the current situation and sometimes because the current workload is too demanding to respond immediately. As a specific example, consider a setting in which a controller forms the intention to reroute an airplane but cannot do so immediately because the aircraft has not yet cleared traffic or because of ongoing demands. Wickens (2002; see also Nowinski et al., in press) points out that in the cockpit pilots are often cognitively overloaded, which affects their appreciation of the factors that are relevant in the current context (i.e., situation awareness).

Reason (1990) argued that human error is the cause of many catastrophic work accidents. He stated that prospective memory failures are among the most common causes of human error and yet little is known about prospective memory. Although there has been much description of the types of errors that occur in work settings and interesting theorizing about the errors (see Nowinski et al., in press; and Reason, 1990), there is very little experimental research that directly tests the capabilities of the human cognitive system for maintaining intentions over brief intervals.

To help us begin to understand these memory challenges, the laboratory paradigm used in the present research was designed to capture critical features of demanding work situations such as frequent task changes, competing demands on attention, and 
changes in the magnitude of demands throughout the work period (see Nowinski et al., in press). We developed this paradigm for exploration in the same sense that others have used simulated work environments to investigate performance and cognitive processes pertinent to applied settings (cf. Salthouse, Hambrick, Lukas, \& Dell, 1996).

Our research on the fate of briefly delayed intentions bears some formal similarity with research on the Zeigarnik effect. In the classic research, Zeigarnik asked participants to perform a series of tasks, and she allowed participants to complete some of the tasks and interrupted others (i.e., she did not allow them to complete some of the tasks right away). Later, when asked to free recall the names of the tasks, participants recalled more of the uncompleted tasks than the completed tasks (see Mäntylä, 1996). Although there is controversy regarding the reliability of the Zeigarnik effect (Butterfield, 1964; Goschke \& Kuhl, 1993; Marsh, Hicks, \& Bink, 1998), the focus of this research has been to examine retrospective memory for the uncompleted intention (task). By contrast, the interest in the present research is to explore how people remember to self-initiate performance of the uncompleted intention (i.e., prospective memory).

In applied settings there are several dimensions of interest that potentially relate to remembering intentions over brief intervals. One is the demands of the ongoing activities during the retrieval period, which have been shown to be important factors in prospective memory tasks in which participants can respond as soon as the target event occurs (Marsh \& Hicks, 1998; McDaniel et al., 1998, Experiment 3). Another dimension is the length of delay between thinking of the intended action and having the opportunity to perform it. In the present experiment, we examined delays after $5 \mathrm{~s}$ and after $15 \mathrm{~s}$. These delays are in the range of those used in the standard retrospective memory literature examining retention after brief delays (Peterson \& Peterson, 1959). In applied settings, however, one is likely to encounter longer delays as well; thus, we also included 40-s delays.

Borrowing from the classic retrospective memory literature with delays of this magnitude (Brown, 1958; Peterson \& Peterson, 1959; Washburn \& Astur, 1998), one's general expectation might be that memory declines as the length of the delay increases. The existing research in prospective memory has mostly examined delays on the order of minutes and has not found increased forgetting as the delay increases (Einstein, Holland, McDaniel, \& Guynn, 1992; Hicks, Marsh, \& Russell, 2000; Stone, Dismukes, \& Remington, 2001). The two published sets of experiments using a paradigm in which execution of the response must be delayed for a number of seconds ( $5 \mathrm{~s}$ vs. $15 \mathrm{~s}$ and $10 \mathrm{~s}$ vs. $20 \mathrm{~s}$ ) also showed no increases in forgetting over longer delays (Einstein, McDaniel, Manzi, Cochran, \& Baker, 2000; McDaniel, Einstein, Stout, \& Morgan, in press). These initial results stand in contrast to the classic retrospective memory findings, and a major goal of the present research is to examine the forgetting function for briefly delayed intentions.

\section{Theoretical Views}

To develop an initial understanding of how people accomplish remembering in this type of memory task, we considered three alternative views that differ in their assumptions regarding the resource demands of the prospective memory task of interest here.
To develop expectations for the current experiments from these views, we adopted some basic assumptions. The first was that maintaining current concerns in an activated state is a core function of working memory (Engle, Tuholski, Laughlin, \& Conway, 1999) and that when working memory adequately serves this function performance is perfect or nearly perfect. In line with this assumption, working memory is measured by requiring participants to maintain items in memory in the face of interference (Turner \& Engle, 1989; Waters \& Caplan, 1996). A second assumption was that for the prospective memory tasks used in these experiments, participants intend to complete the task (i.e., remember to execute the intention) with $100 \%$ accuracy. Third, in part on the basis of these two assumptions, we assumed that working memory processing facilities would be engaged to support prospective memory in the current task. Fourth, and important, we embraced the idea that the human system possesses finite processing facilities (Navon \& Gopher, 1979; Norman \& Bobrow, 1975). Thus, there is a finite amount of resources that can be devoted to the prospective memory task and the ongoing activities during the retention interval. The views presented next differ in their assumptions regarding the resources demanded by the prospective memory task (for the intended level of performance assumed above), and these differing assumptions lead to different expectations regarding prospective memory performance.

One view is that maintaining the intention in working memory requires minimal resources (we label this the minimal demands view). By minimal demands we do not mean to imply that no rehearsal is needed, because most current views assume that maintaining information in focal awareness does not last more than $2 \mathrm{~s}$ (Muter, 1980; Schweickert \& Boruff, 1986). Therefore, intervals longer than $2 \mathrm{~s}$ are probably the most interesting in terms of examining the fragility of intended actions over delays. For intervals longer than $2 \mathrm{~s}$ most views assume that some type of refreshing of the trace is needed, and it is assumed that this kind of rehearsal (for a single item) is not highly demanding. For example, Keppel and Underwood's study (1962) showed virtually no forgetting of trigrams over 18-s delays of counting backwards for the initial trial (in which proactive interference is minimized). This type of situation parallels the conditions used in the present paradigm, in which there is a single intended action repeated throughout the experiment that must be maintained over a short delay. Further, Baddeley and Hitch (1974) reported that maintenance of up to several items while performing a concurrent complex task (involving comprehension and reasoning) was consistently accomplished with no significant decrement in performance of the concurrent task. From the perspective of Baddeley's (1986) model, the implication is that a rehearsal loop is able to maintain small amounts of information with minimal central executive demands.

Presuming minimal resource demands for maintaining a single intended action in working memory, one would not expect highly demanding ongoing activities (but still within capabilities of the cognitive system) to be a problem for prospective memory. Thus, according to the minimal demands view, prospective memory performance should be quite high throughout the delays examined herein and should not be impacted by interruptions or further demands on the putative central attentional or executive process (cf. Baddeley, 1986; Baddeley \& Hitch, 1974). Experiments 1-3 examined these possibilities. In addition, high performance should 
be achieved with no decrement in performance on the concurrent ongoing activity. Experiments 2 and 3 investigated this issue.

Although the literature indicates that people can hold limited amounts of information over brief periods of distraction for retrospective memory tasks, it may be that the information is not maintained with sufficient activation to support prospective memory. For prospective remembering there is no external agent that prompts the reporting of the maintained information. Consequently, prospective remembering may require higher levels of activation to support remembering than do the standard short-term retrospective memory paradigms, in which recall is always prompted. This view suggests that more than minimal resources are needed to maintain the intention in a sufficiently activated state to support prospective remembering. The key assumption is that it is relatively effortful to maintain the activation of the intention at a level that is sufficiently high to support successful prospective remembering. At this point, the predictions concerning the effects of delays from this view require further consideration of the resource demands of the prospective memory task.

One possibility is that strategically maintaining intentions in working memory even over brief delays requires extensive resources, such that in the presence of the ongoing activity (also requiring resources) the resource demand exceeds supply. Assuming also that in many contexts people are unwilling to compromise performance of the ongoing activity to ensure high levels of prospective memory (i.e., they are not indifferent to substituting prospective memory performance for ongoing task performance; see Navon \& Gopher, 1979), this view suggests that people cannot continually maintain the intention in working memory (see McDaniel \& Einstein, 2000; we label this the prohibitively expensive view.) Accordingly, in these instances prospective memory would instead be highly dependent on the activation level of a briefly activated representation that is not refreshed, thus decaying over time (Cowan, 1999; Reitman, 1974). On the basis of previous work showing that information for which active rehearsal is not possible or is prevented shows a forgetting curve from several seconds through 40 s (Peterson \& Peterson, 1959; Washburn \& Astor, 1998), this perspective anticipates that performance should decline as the delay phase increases in length. This view also predicts no effects on prospective memory of dividing attention because it assumes that people cannot maintain the intention in the first place (without a decline in cover-task performance that is ordinarily unacceptable to participants). Finally, like the minimal demands view, the prohibitively expensive hypothesis predicts no cost to the cover task (this was tested in Experiments 2 and 3).

Another possibility is that maintaining intentions over a retention interval is moderately demanding, perhaps involving periodic activation of the intention. We label this the active maintenance view. People may sneak in rehearsals when the momentary demands of the cover task are relatively low (see, e.g., Reitman, 1974). These strategic retrievals of the intention from long-term memory (cf. Hicks et al., 2000) are likely to require resources (Craik, Govoni, Naveh-Benjamin, \& Anderson, 1996). As well, the activation of the intention could be cued by the ongoing task demands, which may have become associated with the prospective memory intention (Nowinski \& Dismukes, 2003; see also McDaniel et al., 1998). The idea here is that the prospective memory intention co-occurs within an ongoing task context, thereby creating some associative relation such that the ongoing context can cue or activate thoughts concerning the intended action. Although periodic activation of the intention may not require strategic retrieval (e.g., the context may spontaneously cue retrieval of the intention), resources are likely to be required to select and interpret the contextually cued retrieved intention (cf. Einstein et al., 1997; McDaniel \& Einstein, 2000).

As a first approximation, we assumed that these resource demands in conjunction with the demands of a typically demanding ongoing activity are at the limits of people's processing resources. According to this view, increasing the demands of the cover activities (i.e., adding a divided-attention task) should interfere with these periodic activation processes and thus lower prospective memory. Also, to the extent that participants are able to periodically activate the intended action, this view predicts that there will be little effect of the length of the delay. These predictions were tested in Experiment 1. The active maintenance view also raises the possibility that because successful prospective memory performance over brief delays requires higher levels of activation of the intention (than an item prompted for recall at the end of a brief delay), some costs to the ongoing activity will be exacted. Experiments 2 and 3 examined this prediction.

\section{The Experimental Paradigm}

To evaluate the issues outlined above, we conducted three experiments using a novel paradigm. Participants were involved in a series of different activities. At the outset of the experiment, they were told that whenever they saw a red screen, they should press a designated key on the keyboard but not until they finished the current ongoing task. During the experiment, when the red screen appeared, the ongoing task continued for 5-40 s before a task change occurred. The task change was the signal for the execution of the prospective memory action. An important consideration in implementing this basic paradigm was capturing the complex and dynamic character of demanding work situations. Thus, participants received relatively quickly paced tasks, the nature of the task changed every $60 \mathrm{~s}$, and attention was divided during half of the tasks. In addition, in Experiment 1 some delays were interrupted by yet another task, paralleling the complex demands of many work situations (Loukopoulos et al., 2001).

Another general goal of the present research (investigated in Experiments 2 and 3) was to examine the effectiveness of cognitive strategies for improving prospective remembering in these contexts. Given that forgetting of briefly delayed intentions can have dire consequences in many kinds of work settings, there is applied value to finding simple strategies that reduce forgetting in these situations. Although instructing people to use certain strategies has been shown to improve remembering in a variety of retrospective memory contexts (Bellezza, 1981; Bower, 1970), there has been only limited work examining whether cognitive strategies can usefully improve prospective remembering (Camp, Foss, Stevens, \& O'Hanlon, 1996; Chasteen, Park, \& Schwarz, 2001), and there has been no published work with the kind of fast-paced and demanding delay-execute prospective memory task used in the present research.

\section{Experiment 1}

In this experiment we manipulated the length of the delay between the occurrence of the red screen and the end of the 
ongoing task. The delays were 5,15 , and $40 \mathrm{~s}$. We also manipulated whether attentional demands were increased with an additional digit monitoring task during the delay and execution period (i.e., during the task in which the red screen appeared; this carried through the period during which it was appropriate to execute the response).

As outlined above, the minimal demands view assumes that performance should be perfect or nearly perfect, certainly at the shorter 5- and 15-s intervals and possibly at the 40-s interval. Because the intention is assumed to be easily maintained in working memory, distraction during the execution period would also not be expected to impair performance. The prohibitively expensive view, by contrast, predicts no effects of dividing attention (because participants cannot maintain the intention even in the standard attention condition), relatively low prospective memory performance, and greater forgetting of the intention with longer delays. In contrast, according to the active maintenance view, prospective memory performance should suffer when the attentional demands during the delay period are high. To the extent that participants are able to maintain some activation of the intention over the delay even with heavy demands during the delay period, this view predicts modest levels of memory loss at all delays.

Another goal of this experiment was to collect initial data on the effects of a brief interruption during the delay period. We did this by requiring participants to interrupt their performance of the ongoing task and switch attention to a brief 15 -s additional task during some of the 40-s delay intervals. Real-world work situations are filled with short interruptions (Dismukes et al., 1998; Loukopoulos et al., 2001), and it is important to understand the effects of such interruptions on maintaining intentions. Further, examining the effects of interruptions provided additional leverage for informing the theoretical views developed in this article. Because of the need to suspend the current task, orient toward new instructions, and begin a new task, we assumed that interruptions create resource demands for the cognitive system (Monk, BoehmDavis, \& Trafton, 2002). Thus, we hypothesized that the effect of interruptions should be similar to that of dividing attention. If maintaining intentions requires minimal resources or is prohibitively demanding, however, interruptions should have relatively little effect on prospective memory.

The active maintenance view makes the more complex prediction that interruptions should reduce prospective memory primarily when the ongoing activity produces few resource demands. The idea is that participants should find it difficult to actively maintain the intention with high demands (i.e., divided attention during the delay phase) during the delay periods, and thus additional demands associated with the interruption should have relatively little effect on prospective remembering.

\section{Method}

Design and participants. The design of this experiment was a $2 \times 4$ mixed factorial in which the attentional demands (standard, divided) were varied between subjects, and the length and type of delay (5-s, 15-s, 40-s, and 40-s with interruption) were varied within subjects. Participants were either general psychology students at Furman University who received course credit for participating or volunteers from the general student population who received $\$ 8$. Twenty participants were randomly assigned to each of the two groups, and each participant was tested individually. When questioned at the end of the experiment, 2 participants who indicated that they did not fully comprehend the instructions were replaced with 2 other participants.

Procedure and materials. Our goal was to create an experimental procedure that was demanding and complex, and because of the potential confusion in performing several tasks simultaneously, the instructions for each task were presented thoroughly and for one task at a time. Each set of instructions was first read from the computer monitor by the participant and then explained by the experimenter if necessary. Then participants were asked to repeat the instructions back to the experimenter. Participants were also given the opportunity to ask questions before receiving the next set of instructions. In addition, they were told that every aspect of the experiment was equally important and that they should try to perform perfectly on all tasks.

Participants were first told about the following eight cover tasks that would be presented via computer: (a) Rate on a 5-point scale how well an object fits a given category, (b) answer four-choice trivia questions, (c) compute math problems and select the answer among the five choices, (d) choose the best synonym (among five choices) for a given word, (e) judge which of two lines is longer, (f) rate the pleasantness of a word on a 5-point scale, (g) identify a partially occluded object by choosing among three alternatives, and (h) rate the similarity of a pair of words on a 5-point scale. A heading (e.g., TRIVIA) appeared at the top of each screen to identify the task. Participants were shown an example of each kind of task and given the opportunity to ask questions.

Participants were instructed to call out the number corresponding with their choice on each trial and to simultaneously press a designated key (labeled with an asterisk) on the response box in front of them. They were told to use their preferred hand (i.e., right-handed participants were instructed to press the key with their right hand, and left-handed participants with their left hand), and we moved the response box to a comfortable position for each participant. Participants were told that their response latencies would be recorded when they pressed the key on the response box and thus that they should try to respond as quickly as possible. In truth, the response box was not connected to anything, and we included this as part of the cover-task procedure to keep the hands of the participants occupied. During pilot work, we noticed that some participants used their fingers as external cues (e.g., crossing their fingers whenever a prospective memory task occurred), and we wanted to eliminate this reliance on external mneumonic strategies. Cover-task items were presented in sets of 12 trials, and each trial was presented for $5 \mathrm{~s}$. Therefore, a given cover task lasted 1 min, and this was followed by a new cover task. Each cover task was presented four times for a total of $32 \mathrm{~min}$.

Next, all participants were told about the digit-monitoring task, which was used to divide attention. For half of the participants, attention was divided during the delay and execution phases of the prospective memory trials and for the other half, attention was divided during nonprospective memory trials. Participants were told that during some trials, they would hear a series of single digits presented at the rate of one every $2 \mathrm{~s}$ and that they should press a counter (with their nonpreferred hand) every time they heard two odd-digit numbers consecutively. They held the digit counter throughout the experiment, and they were strongly encouraged to detect every occurrence of the consecutive odd-numbered digits. Participants were given a 30 -s practice trial with this task.

Participants were then given the prospective memory instructions (delayed execution task). They were told that during some of the trials, a red screen would appear on the computer monitor for $1 \mathrm{~s}$ and that when this occurred, they should press the slash key (/) on the computer keyboard but not until they finished the current task. Examples of 5-s and 15-s delay trials are shown in the first two columns of Table 1. Participants were told to use their preferred hand (i.e., the one used for the response box) to press the slash key. To ensure that participants understood the instructions, they were given a practice trial (with no digit monitoring) in which the experimenter paced them through sheets in a folder that contained two math problems followed by a red sheet, followed by four math problems, 
Table 1

Sequence of Events for 5-s Delay, 15-s Delay, and 40-s Delay With Interruption Trials

\begin{tabular}{|c|c|c|}
\hline 5-s delay & 15-s delay & 40-s delay with interruption \\
\hline Math problem 1 & Math problem 1 & Math problem 1 \\
\hline - & - & - \\
\hline Math problem 12 & Math problem 12 & Math problem 12 \\
\hline Category problem 1 & Category problem 1 & Category problem 1 \\
\hline - & - & - \\
\hline Category problem 9 & Category problem 9 & Category problem 4 \\
\hline Category problem 10 & Red screen & Red screen \\
\hline Category problem 11 & Category problem 10 & Category problem 5 \\
\hline Red screen & Category problem 11 & Category problem 6 \\
\hline Category problem 12 & Category problem 12 & $\begin{array}{l}\text { Go to FOLDER } \\
\text { (15 } \mathrm{s} \text { of pattern comparison) }\end{array}$ \\
\hline $\begin{array}{l}\text { Synonym problem } 1 \\
\text { (cue for pressing slash key) }\end{array}$ & $\begin{array}{l}\text { Synonym problem } 1 \\
\text { (cue for pressing slash key) }\end{array}$ & Category problem 10 \\
\hline - & 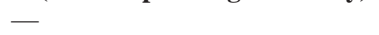 & Category problem 11 \\
\hline Synonym problem 12 & Synonym problem 12 & Category problem 12 \\
\hline Trivia problem 1 & Trivia problem 1 & $\begin{array}{l}\text { Synonym problem } 1 \\
\text { (cue for pressing slash key) }\end{array}$ \\
\hline- & - & $\begin{array}{l}\text { Synonym problem } 12 \\
\text { Trivia problem } 1\end{array}$ \\
\hline
\end{tabular}

Note. The occurrence of the red screen and the cue for performing the prospective memory action are shown in bold. Dashes represent intervening intervals.

followed by a trivia item. Participants were told that in this set of trials they should press the slash key when the task changed from the math to the trivia items. Participants were then asked to repeat the instructions back to the experimenter, asked to locate the slash key on the keyboard, and given the opportunity to ask questions. The experimenter reminded the participants that they would at times also have to perform the digit-monitoring task.

Finally, participants were told about the interruption task. Specifically, they were told that on some trials, another screen would appear displaying the message go to FOLDER. Whenever they encountered this screen, they were to stop performing the current cover task, open the folder (located beside the computer keyboard) containing a pattern-comparison test (developed by Salthouse \& Babcock, 1991). They were told to continue performing this task as long as the go to FOLDER message remained on the screen. Participants were told to do this with their preferred hand (the one normally on the response box). The items in the pattern comparison test involved judging whether paired line drawings were the same or different by writing either an $S$ or a $D$ in the blanks provided. While participants were performing this activity, they also had to monitor the computer screen to determine whether they needed to resume the cover task. These folder interruptions occurred twice during the experiment, lasted for $15 \mathrm{~s}$, and occurred during a 40-s prospective memory delay trial. As can be seen in the third column of Table 1, the exact sequence on these trials was as follows: 4 trials of a new cover task ( $5 \mathrm{~s}$ per trial), the occurrence of the red screen ( $1 \mathrm{~s}), 2$ trials of the same cover task ( $5 \mathrm{~s}$ each), the go to FOLDER screen for $15 \mathrm{~s}, 3$ trials of the same cover task ( $5 \mathrm{~s}$ each), and the switch to a set of 12 trials with the new cover task ( $5 \mathrm{~s}$ each). After receiving the interruption instructions, participants were shown examples of the perceptual speed task items and given the opportunity to ask questions. They were also told that they should not ignore the digitdetection task while performing the pattern-comparison task.

Before beginning the experiment, participants were once again asked to tell the experimenter what they were supposed to do when a red screen occurred. They were also reminded of the cover task, the digit-monitoring task, and the go to FOLDER task, and then given the opportunity to ask any final questions before beginning the test trials. They were also reminded that all of the tasks in the experiment were equally important and that they should strive to perform perfectly on all of the tasks.
As noted earlier, each set of 12 trials for a cover task lasted 1 min, and each of the eight tasks was presented four times for a total of $32 \mathrm{~min}$. Each type of cover task occurred once within each block of eight tasks; the order of these tasks was determined randomly and was constant for all participants. For all participants, the signal to form an intention over a delay (red screen) occurred during Tasks 3, 6, 11, 15, 18, 21, 26, and 30. Thus, four of these (one of each type: $5 \mathrm{~s}, 15 \mathrm{~s}, 40 \mathrm{~s}$, and $40 \mathrm{~s}$ with interruption) occurred within the first 16 tasks and four occurred within the last 16 tasks. To distribute the influence of factors such as fatigue, practice, and task difficulty across the delay conditions, we created four counterbalancing orders such that across orders each type of delay occurred equally often at each task position (i.e., Tasks 3, 6, 11, 15, 18, 21, 26, and 30). One quarter of the participants in each condition was assigned to each of these orders.

For all participants, the digit-monitoring task was present during half of the cover tasks (i.e., during 16 of the 32 tasks). For participants in the standard-attention condition, the digits did not occur during the delay or execution trials of any of the eight prospective memory trials. In the divided-attention condition, the digit-monitoring task occurred during both the delay and execution phases of all eight of the prospective memory trials. Following the 32 test trials, participants completed a brief questionnaire that prompted them to write down what they were to do whenever a red screen occurred. This was intended to determine whether failures to perform were related to problems in remembering the general task instructions (a retrospective memory problem) or in remembering to perform the delayed intention (a prospective memory problem). They were also asked whether, upon seeing the red screen, they had tried to rehearse the intention to press the slash key or whether they had simply let it "pop into mind."

\section{Results}

Prospective memory. For the analyses throughout this article, an alpha level of .05 was used to infer statistical significance. Also, $\omega^{2}$ was used to indicate effect size in cases in which the $F$ value was greater than 1.0. Because $\omega^{2}$ is an unbiased estimate of the proportion of variance accounted for (Maxwell \& Delaney, 2004), we applied Cohen's (1988) heuristic for classifying proportion of variance as small (0.01), medium (0.09), and large (0.25) effects 
(Cohen specifically referred to $r^{2}$ for which $\omega^{2}$ is an unbiased estimate). For each participant, we tabulated the proportion of times (out of two) that participants remembered to press the slash key during the execution period for each of the four types of delay $(5 \mathrm{~s}, 15 \mathrm{~s}, 40 \mathrm{~s}$, and $40 \mathrm{~s}$ with interruption). Although we scored a prospective memory response as correct if it occurred any time within the 1-min execution period, the great majority of responses (95\%) occurred during the first 5-s trial of the execution period.

Initially, these data were submitted to a $2 \times 3$ mixed analysis of variance (ANOVA) that included the between-subjects variables of attentional demands (standard, divided) and the within-subjects variable of length of the delay ( $5 \mathrm{~s}, 15 \mathrm{~s}, 40 \mathrm{~s})$. The interruption trials were included in a separate analysis that is described later. As shown in Table 2, there was a significant effect (of medium magnitude) of dividing attention. As can be seen in Figure 1, participants in the divided condition $(M=0.76)$ remembered to make the prospective memory response less often than did those in the standard condition $(M=0.92)$. There was no evidence of decreased memory over longer delays despite having high power to detect a large effect (for retrospective memory, over delays similar to those in the present research, the effect size of delay is typically large; e.g., Washburn \& Astur, 1998). In the present experiment, the power to detect a large effect of delay was .99 . There was no indication of an interaction of large magnitude between delay and any of the other variables.

In the next analysis we examined the effects of interruptions by comparing prospective memory performance on the interrupted and the noninterrupted 40-s delay trials (see means in Figure 2). Specifically, we conducted a $2 \times 2$ mixed ANOVA that included the between-subjects variable of attentional demands (standard, divided) and the within-subjects variable of interruption (40-s noninterrupted, 40-s interrupted). As shown in Table 3, this analysis revealed that interruptions significantly (an effect of small magnitude) lowered prospective memory performance $(M=.80$ with no interruption, and $M=.55$ with an interruption). There was also a significant interaction between the presence of an interruption and attentional demands. As can be seen in Figure 2, the decrement in prospective memory associated with an interruption was significantly more pronounced (a small effect) when attention was not divided $(M=.90$ with no interruption, and $M=.58$ with an interruption) than when attention was divided $(M=.75$ with no interruption, and $M=.70$ with an interruption).

Table 2

Analysis of Variance for Prospective Memory Scores in Experiment 1

\begin{tabular}{lccc}
\hline \multicolumn{1}{c}{ Source } & $d f$ & $F$ & $\omega^{2}$ \\
\hline \multicolumn{4}{c}{ Between subjects } \\
Divided attention (DA) & 1 & $9.52^{* * *}$ & .18 \\
S/DA (error) & 38 & $(.09)$ & \\
\hline \multicolumn{4}{c}{ Within subjects } \\
Delay (D) & 2 & 0.53 & \\
DA $\times$ D & 2 & 0.13 & - \\
S $\times$ D/DA (error) & 76 & $(.13)$ & - \\
\hline
\end{tabular}

Note. Values in parentheses represent mean-square errors A dash represents an undefined $\omega^{2}$ when $F<1.0 . \mathrm{S}=$ participants. $* * p<.01$.
Other measures. A two-group ANOVA (comparing the standard and divided conditions) was performed on the proportion of consecutive odd-numbered digits detected by participants. On average, participants detected $81.93 \%$ of the digits, and this did not vary significantly as a function of the groups $(F<1)$. These percentages should be interpreted cautiously, however, because we were only able to count the total number of counter presses; we could not determine their accuracy.

When queried at the end of the experiment, all participants remembered what they were supposed to do when they saw a red screen and that they were supposed to press a key when they encountered a task change. One participant pressed the space bar instead of the slash key, and we counted this as correct because it reflected memory for performing an action after a brief delay (which was the major interest of this research). Also, all participants remembered to press the key on at least one of the eight prospective memory trials. Thus, it appears that participants understood the instructions and that failures to press the key at a task change were the result of prospective memory failures rather than problems associated with understanding or remembering the task demands.

We scored responses from the postexperiment questionnaire with a 0 if participants indicated that they did not try to rehearse and a 1 if they indicated that they tried to rehearse the intention over the delay period. These scores were included in a two-group ANOVA (standard versus divided attention). On average, $57 \%$ of the participants indicated that they tried to rehearse over the delay period, but this percentage varied across conditions, $F(1,38)=$ $5.44, M S E=.03, \omega^{2}=0.10$. Participants indicated that they were less likely to rehearse when attention was divided during the delay period $(M=.40)$ than under the standard condition $(M=.75)$. These data suggest that participants were better able to use a rehearsal strategy when attention was not divided.

\section{Discussion}

The results indicate that participants can maintain intentions at a high rate $(92.5 \%)$ over brief intervals under standard conditions (although in some work settings, a 7.5\% forgetting rate is cause for concern), that especially demanding conditions significantly increase forgetting (by about 17\%), and that the length of the delay has no effect. This latter effect is in sharp contrast to the large and progessive losses in retrospective memory over similar delays (Washburn \& Astur, 1998). The effects of dividing attention occurred at 5-s delays and showed no significant decline after that The effects of divided attention as well as the failure to find increased loss of memory over longer delays were most consistent with the active maintenance view. The idea here is that resources are useful for maintaining intentions, even at the brief 5-s delays, and for supporting activation of the intention over a 40-s delay. According to this view, dividing attention interferes with memory for the intention because it reduces the resources available for maintaining the activation of the intention.

The current results also provide insights into the effects of interruptions on remembering intentions over brief delays. On the assumption that interruptions create resource demands to process the interruption, both the minimal demands view and the prohibitively expensive view predicted no effects of interruptions. The finding that brief 15 -s interruptions were disruptive to prospective 


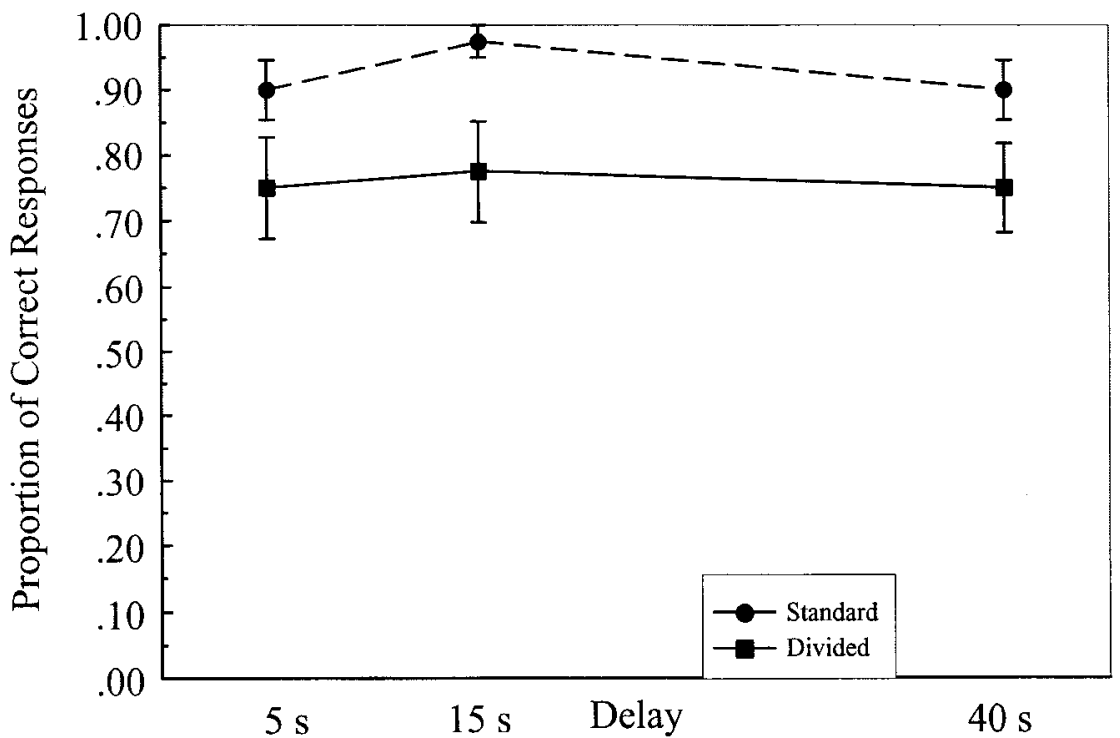

Figure 1. Mean proportion of correct prospective memory responses as a function of delay and attentional demands (standard, divided) in Experiment 1 (error bars represent the standard error).

memory performance, especially when the attentional demands during the delay period were moderate, supports the active maintenance view. According to this view, the effect of interruptions on prospective remembering should be more pronounced when participants have sufficient resources to actively maintain the intention (moderate attention) relative to divided attention.

\section{Experiment 2}

Both the minimal demands view and the prohibitively expensive view assume that people allocate minimal resources to maintaining intentions over brief delays, either because the maintenance of intentions does not require substantial resources (minimal de-

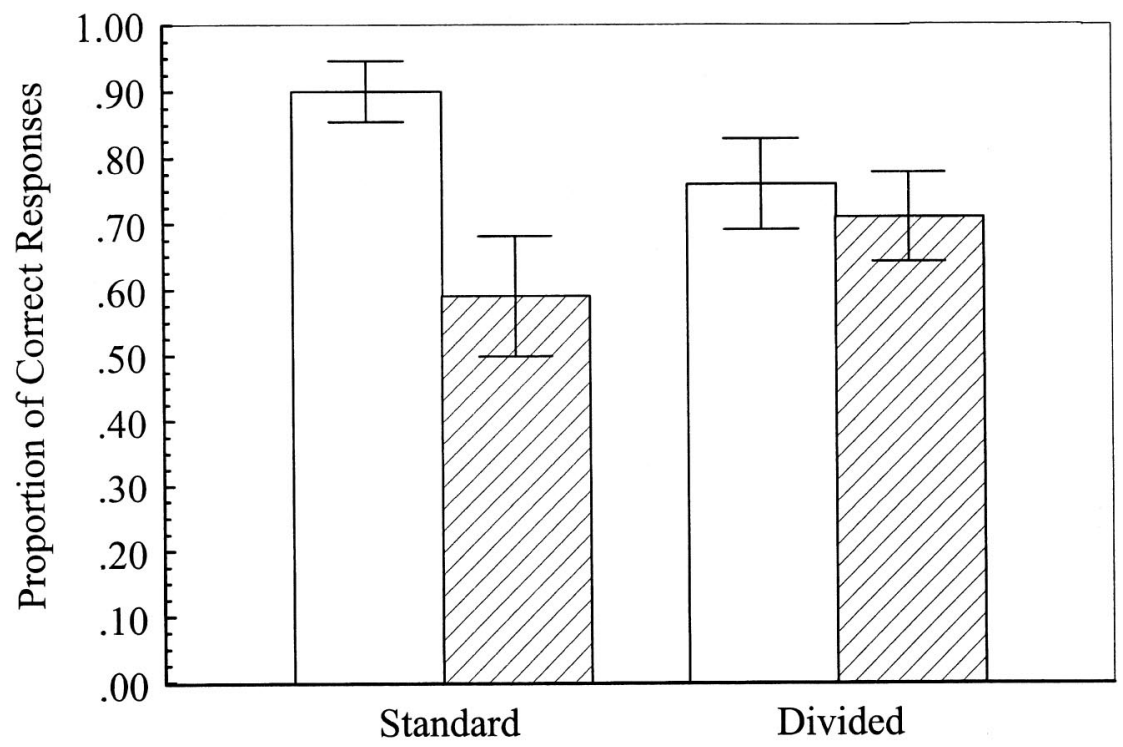

Attentional Demands

Figure 2. Mean proportion of correct prospective memory responses as a function of the presence of an interruption and attentional demands in Experiment 1 (error bars represent the standard error). Open bars represent no interruption; hatched bars represent interruption. 
Table 3

Analysis of Variance Examining the Effects of Interruptions on Prospective Memory Scores

\begin{tabular}{lccc}
\hline \multicolumn{1}{c}{ Source } & $d f$ & $F$ & $\omega^{2}$ \\
\hline \multicolumn{4}{c}{ Between subjects } \\
Divided attention (DA) & 1 & 0.03 & \\
S/DA (error) & 38 & $(.13)$ & \\
\hline \multicolumn{4}{c}{} \\
Interruption (I) & Within subjects & & \\
DA $\times$ I & 1 & $10.54^{* *}$ & .08 \\
$\mathrm{~S} \times$ I/DA (error) & 1 & $5.65^{*}$ & .04 \\
\hline
\end{tabular}

Note. Values in parentheses represent mean square errors. A dash represents an undefined $\omega^{2}$ when $F<1.0 . \mathrm{S}=$ participants.

$* p<.05$. ** $p<.01$.

mands) or because participants cannot do so (prohibitively expensive). The active maintenance view, by contrast, assumes that participants try to actively maintain the intention in working memory to support the self-initiated retrieval required for prospective remembering. In the next experiment, we evaluated these theories by examining the costs of maintaining an intention on the accuracy as well as the speed of performing the cover-task activities. Following Reitman (1974) and the assumption sketched in the introduction about the conjoint resource demands of periodic activation and the cover task (see also Guynn, 2002; Smith, 2003), to the extent that participants sneak in rehearsals to maintain the activation of the intention, cover-task performance should be compromised.

From an applied perspective, it is important to know whether there are fairly simple cognitive strategies that one can rely on to improve remembering intentions over brief delays. One intuitively obvious strategy is to warn people of the importance of actively maintaining intentions over delays and to encourage them to rehearse. Thus, in addition to the normal control instructions used in the divided condition in Experiment 1, we included a rehearsal group that was explicitly warned about the difficulty of maintaining intentions over brief delays and instructed to actively rehearse the phrase "task change-press key" over the delay period. Both groups performed their cover activities under conditions of high ongoing activity that were similar to the demanding condition of Experiment 1.

According to the active maintenance view, encouraging rehearsal under demanding conditions may be relatively ineffective. Our assumption is that control participants normally try to sneak in rehearsals within the constraints allowed by the cover task and that when the demands of the ongoing activity are high, the rehearsal process is sufficiently demanding such that participants cannot devote additional rehearsal while performing the highly demanding ongoing activity.

\section{Method}

Design and participants. The design of this experiment was a $2 \times 3$ mixed factorial in which the type of prospective memory instructions (control, rehearsal) was varied between subjects and the length of the delay $(5 \mathrm{~s}, 15 \mathrm{~s}, 40 \mathrm{~s})$ was varied within subjects. Participants were Furman University students who received either \$6 or General Psychology course credit for their participation. Twenty participants were randomly assigned to each of the two groups, and all were tested individually. One participant was dropped and replaced because we discovered at the end of the experiment that the participant did not fully understand the task demands.

Procedure and materials. The procedure and the materials were modeled closely after those used in the first experiment. Several changes were made, however, to enable us to evaluate the cost of performing a prospective memory task on the accuracy and speed of performing the cover task. As in the first experiment, all eight cover tasks were presented with each task consisting of 12 trials ( $5 \mathrm{~s}$ each) lasting $1 \mathrm{~min}$. Rather than calling out their answers, participants answered each question with their preferred hand using the number pad positioned at the far right of the keyboard. Each cover task was presented 3 times with the exception of the categoryjudgment task, which was presented 10 times for a total of $31 \mathrm{~min}$ of cover-task trials.

We modified the category-judgment task in this experiment to clearly determine whether an answer was correct or incorrect. In this revised task, participants decided how many items out of four fit a given category heading. With this change, we were able to examine whether maintaining an intention affected the accuracy (as well as the speed) of performing this task. With the exception of the category-judgment task, the order of the cover tasks was determined randomly and remained constant for all participants. The prospective memory cue (the red screen) occurred only during the category-judgment task. Eight of these were designated as target tasks (Tasks 3, 7, 11, 15, 18, 21, 25, and 30), and two were selected for a 5-s delay, two for a 15-s delay, two for a 40-s delay, and two for control trials. The two control trials enabled us to determine performance on the category-judgment task without the additional burden of performing a prospective memory task. One of each type of trial (5 s, $15 \mathrm{~s}, 40 \mathrm{~s}$, and control) occurred within the first half of the task (Tasks 3, 7, 11, and 15), and one occurred in the last half of the task (Tasks 18, 21, 25, and 30). The items for a particular category task trial were always the same, but the order of the items was determined randomly for each participant. The order of the cover task trials was constant for all participants. Four counterbalanced orders, with 5 participants receiving each, were created so that across all orders each prospective memory delay (and control) was associated with each category-judgment task an equal number of times.

After receiving their instructions concerning the cover-task activities, participants were given instructions about the divided-attention task, which in this experiment was a digit-load task. Specifically, they were told that they would occasionally be presented with a set of six digits to memorize and have to hold them in memory until they encountered a screen indicating "Recall Digits Now." At encoding, the digits were presented for $5 \mathrm{~s}$ in the center of the computer screen, and at test, participants were to type in the six digits (or as many as they could remember) on the keypad at the far right of the keyboard. Participants were given a practice trial with this digit task, and they were told to keep the hand that they were not using in their lap for the duration of the experiment. This was done to prevent people from using that hand as an external cue for the prospective memory task. Participants were told that the digit task was as important as any other task and that it was imperative for them to try to remember the digits. Twelve sets of digits were presented across the 31 cover-task trials, always at the beginning of a new cover task. For 9 of these trials, participants were required to hold the digits in memory for $2 \mathrm{~min}$, and for 3 of the trials, they were tested after a 1-min delay. The positioning of these digit-load trials always was such that participants were holding digits in memory during the delay and execution phases of both the prospective memory trials and the control trials. Thus, in this experiment, both groups of participants were always tested under conditions analogous to the divided condition of Experiment 1 .

The postexperimental questionnaire was the same as that used in Experiment 1 except that participants rated the degree to which they rehearsed the delayed intention on a 5-point scale using the anchors of 1 (let it pop into mind) and 5 (rehearsed). The intervening numbers were not labeled. 


\section{Results}

Prospective memory. We tabulated the proportion of correct prospective memory responses (occurring any time during the 1-min execution period) for each of the delays and included these in a $2 \times 3$ mixed ANOVA that tested the between-subjects effects of instructional condition (control, rehearsal) and within-subjects effects of delay ( $5 \mathrm{~s}, 15 \mathrm{~s}, 40 \mathrm{~s})$. As shown in Table 4, this analysis revealed that strong rehearsal instructions did not improve prospective memory. Indeed, as can be seen in Figure 3, performance was nominally lower in the rehearsal condition $(M=.84$ and .76 for the control and rehearsal conditions, respectively). We used Faul and Erdfelder's (1992) GPOWER for the power analyses for the between-subjects effects, and our power to detect a medium effect size was .33. Our expectation of an effect of this magnitude was based on Chasteen et al.'s (2001) findings that an instructed cognitive strategy produced a benefit of medium effect size on prospective memory. Consistent with the results of the first experiment, there was no significant effect of delay despite having sufficient power (.93) to detect a large effect. There was no hint of an interaction of large magnitude among the variables.

Cover-task performance. To examine the possible costs of maintaining an intention over delays on cover-task performance, we tabulated the proportion of cover task (i.e., category-judgment task) items answered correctly over the 5-s, 15-s, and 40-s prospective memory delays. For comparison, we also calculated the proportion of cover-task items correctly answered during the two control category-judgment tasks. Using these trials, we calculated performance for the equivalent of the 5-s condition (i.e., last item in the set), the 15-s condition (i.e., last three items in the set), and the 40-s condition (i.e., last eight items in the set). The data from the control and prospective memory trials were included in a $2 \times$ $3 \times 2$ mixed ANOVA that included the between-subjects variable of instructional condition (control, rehearsal) and the withinsubjects variables of delay $(5 \mathrm{~s}, 15 \mathrm{~s}, 40 \mathrm{~s})$ and type of trial (control, prospective memory). As shown in Table 5, this analysis produced a small but significant effect of type of trial such that participants answered a greater proportion of the cover items correctly when they were not maintaining an intention over the delay interval (for control trials, $M=.62$ ) than when they were (for prospective memory trials, $M=.55$ ). This effect did not interact with delay or instruction condition, and there was no significant effect of delay (see Table 6 for means).

Table 4

Analysis of Variance for Prospective Memory Scores in Experiment 2

\begin{tabular}{lcll}
\hline \multicolumn{1}{c}{ Source } & $d f$ & $F$ & $\omega^{2}$ \\
\hline \multicolumn{4}{c}{ Between subjects } \\
Instruction (I) & 1 & 1.54 & .01 \\
S/I (error) & 38 & $(.14)$ & \\
\hline \multicolumn{4}{c}{ Within subjects } \\
Delay (D) & 2 & 1.02 & .00 \\
$\mathrm{I} \times \mathrm{D}$ & 2 & 0.65 & - \\
$\mathrm{S} \times \mathrm{D} /$ I (error) & 76 & $(.08)$ & \\
\hline
\end{tabular}

Note. Values in parentheses represent mean square errors A dash represents an undefined $\omega^{2}$ when $F<1.0 . \mathrm{S}=$ participants.
We also examined the cost of maintaining an intention on the speed of performing the cover activities. To do this, we tabulated the mean speed of responding on correctly answered trials for 5-s, 15 -s, and 40-s prospective memory delays and for the equivalent delays in the control trials after removing response times (less than $5 \%$ ) that were more than two standard deviations from the mean (Ratcliff, 1979). Nearly all of the omitted response times were extremely brief and probably represented late responses to the prior item. Because some participants did not have a correct, and thus a usable, response time for the 5-s and 15-s delays, the data were analyzed in three separate (one for each delay) $2 \times 2$ mixed ANOVAs that included the between-subjects variable of instructional condition (control, rehearsal) and the within-subjects variable of presence of a prospective memory task (control, prospective memory).

Fourteen control and 11 rehearsal-condition participants were included in the analysis of response times for the 5-s delay. As shown in Table 7, this analysis revealed that the presence of a prospective memory task had a small but significant effect on response times on the cover task. As can be seen in Table 6, participants were slower to respond to the cover-task items on prospective memory trials than they were on nonprospective memory trials. There was no statistical evidence that this effect interacted with instructional condition and no overall difference between instructional conditions.

Twenty control-condition and 18 rehearsal-condition participants were included in the analysis of response times over the 15-s delay, and all 20 participants in each group were included in the analysis for the 40-s delay. As shown in Table 7, neither analysis produced significant effects. Thus, response times were not significantly faster on control relative to prospective memory trials, response times were not significantly slower in the rehearsal relative to the control condition, and there was no evidence of an interaction between these variables.

Other measures. We examined performance on the digit-load task by tabulating the proportion of digits participants recalled correctly. These proportions were used in a $2 \times 4$ mixed ANOVA that included the between-subjects variable of instructional condition (control, rehearsal) and the within-subjects variable of type of trial (5-s delay, 15-s delay, 40-s delay, and control). On average, participants recalled $83 \%$ of the digits, and this did not vary as a function of condition, type of trial, or both (all $F \mathrm{~s}<1$ ).

When queried at the end of the experiment, all participants indicated that they understood what they were to do upon seeing a red screen. Also, all participants remembered to press the key on at least one of the six memory trials. Thus, it appears that forgetting was due to prospective, and not retrospective, memory problems.

In the postexperiment questionnaire participants rated the extent to which they rehearsed the intention on a 5-point scale ranging from 1 (let it pop into mind) to 5 (rehearsed), and these ratings were included in a two-group ANOVA (control vs. rehearsal instructions). Mean ratings for the control and rehearsal conditions were 3.30 and 4.15 respectively, and this difference was significant, $F(1,38)=10.26, M S E=.70, \omega^{2}=.18($ an effect of medium magnitude). Thus, on average, participants indicated that they tended to rehearse the delayed intention and especially so in the rehearsal condition. 


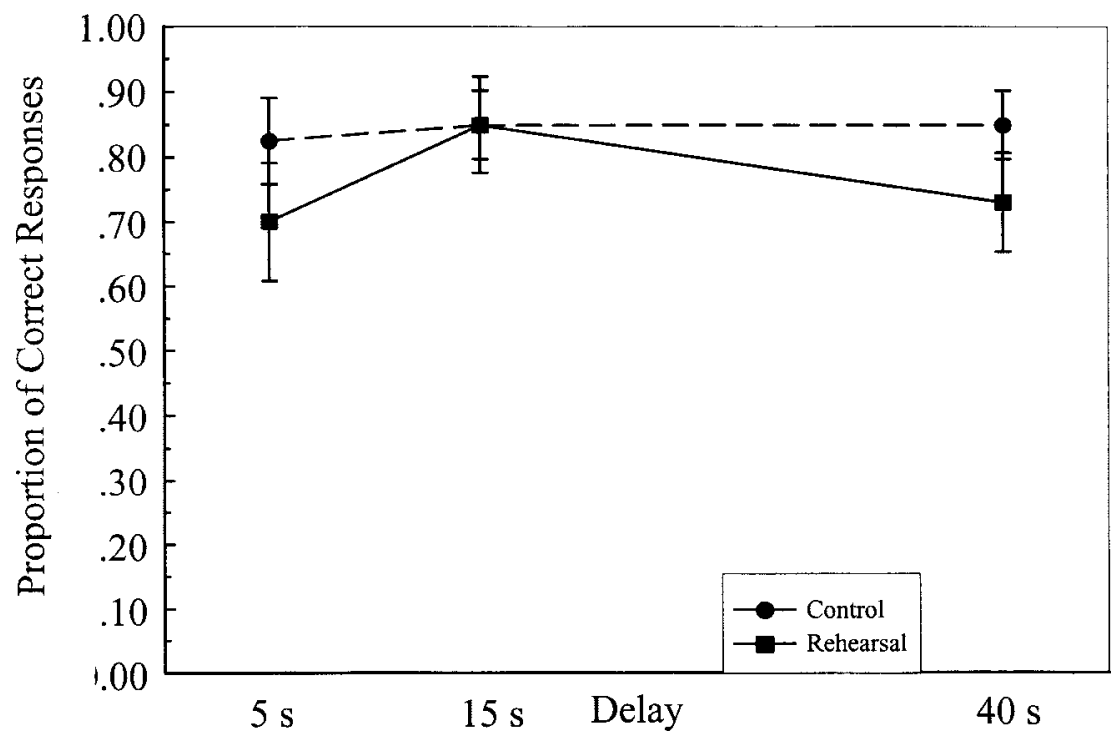

Figure 3. Mean proportion of correct prospective memory responses as a function of delay and rehearsal condition in Experiment 2 (error bars represent the standard error).

\section{Discussion}

The results showing costs of maintaining an intention over a delay on the accuracy and speed (at least at the 5-s delay) of performing the cover-task activities are consistent with the effects of dividing attention in the first experiment and show that people normally allocate resources to the task of maintaining intentions over brief delays. As such, these results support the active maintenance view and not the minimal demands view or the prohibitively expensive view.

One might have presumed that informing individuals to rehearse the intended activity would increase the likelihood of remembering that activity. Our results, however, reveal that simply warning participants and instructing them to rehearse produces no signifi-

Table 5

Analysis of Variance for Cover Items Answered Correctly in Experiment 2

\begin{tabular}{lccc}
\hline \multicolumn{1}{c}{ Source } & $d f$ & $F$ & $\omega^{2}$ \\
\hline \multicolumn{4}{c}{ Between subjects } \\
Instruction (I) & 1 & 0.20 & \\
S/I (error) & 38 & $(.24)$ & \\
\hline \multicolumn{4}{c}{ Within subjects } \\
Delay (D) & 2 & 0.78 & - \\
$\mathrm{I} \times \mathrm{D}$ & 2 & 0.70 & - \\
$\mathrm{S} \times \mathrm{D} / \mathrm{I}$ (error) & 76 & $(0.05)$ & .02 \\
Trial type (T) & 1 & $4.39^{*}$ & - \\
$\mathrm{I} \times \mathrm{T}$ & 1 & 0.82 & .00 \\
$\mathrm{~S} \times \mathrm{T} / \mathrm{I}$ (error) & 76 & $(0.07)$ & - \\
$\mathrm{D} \times \mathrm{T}$ & 2 & 1.45 & \\
$\mathrm{D} \times \mathrm{T} \times \mathrm{I}$ & 2 & 0.62 & \\
$\mathrm{~S} \times \mathrm{D} \times \mathrm{T} / \mathrm{I}$ (error) & 76 & $(0.05)$ & \\
\hline
\end{tabular}

Note. Values in parentheses represent mean square errors. A dash represents an undefined $\omega^{2}$ when $F<1.0 . \mathrm{S}=$ participants. $* p<.05$. cant benefits beyond that of control instructions. The results suggest that participants, regardless of whether they receive special instructions, are unable under demanding conditions to maintain the activation of the intention at levels that are sufficiently high to support nearly perfect prospective remembering. The resource requirements of the cover-task activities seem to interfere with this kind of maintenance.

\section{Experiment 3}

Participants have more difficulty actively maintaining an intention when the task demands are high, and simple warnings and

Table 6

Accuracy and Speed of Cover-Task Performance as a Function of Instructional Condition, Delay, and Type of Trial in

Experiment 2

\begin{tabular}{|c|c|c|c|}
\hline \multirow{2}{*}{$\begin{array}{l}\text { Instructional condition } \\
\text { and type of trial }\end{array}$} & \multicolumn{3}{|c|}{ Delay } \\
\hline & $5 \mathrm{~s}$ & $15 \mathrm{~s}$ & $40 \mathrm{~s}$ \\
\hline \multicolumn{4}{|c|}{ Proportion of category-task items answered correctly } \\
\hline \multicolumn{4}{|c|}{ Control } \\
\hline Control & .60 & .66 & .60 \\
\hline Prospective & .55 & .59 & .59 \\
\hline \multicolumn{4}{|l|}{ Rehearsal } \\
\hline Control & .65 & .63 & .58 \\
\hline Prospective & .45 & .53 & .58 \\
\hline \multicolumn{4}{|c|}{$\begin{array}{l}\text { Speed (in ms) of category-task performance for items answered correctly } \\
\text { Control }\end{array}$} \\
\hline Control & 3,163 & 3,332 & 3,360 \\
\hline Prospective & 3,487 & 3,394 & 3,373 \\
\hline \multicolumn{4}{|l|}{ Rehearsal } \\
\hline Control & 3,209 & 3,472 & 3,448 \\
\hline Prospective & 3,608 & 3,673 & 3,529 \\
\hline
\end{tabular}


Table 7

Analyses of Variance for Response Times to Correctly Answered Cover-Task Items in Experiment 2

\begin{tabular}{|c|c|c|c|c|c|c|c|c|c|}
\hline \multirow[b]{2}{*}{ Source } & \multicolumn{3}{|c|}{ 5-s delay } & \multicolumn{3}{|c|}{15 -s delay } & \multicolumn{3}{|c|}{ 40-s delay } \\
\hline & $d f$ & $F$ & $\omega^{2}$ & $d f$ & $F$ & $\omega^{2}$ & $d f$ & $F$ & $\omega^{2}$ \\
\hline & & & \multicolumn{3}{|c|}{ Between subjects } & & & & \\
\hline Instruction (I) & 1 & 0.16 & - & 1 & 2.04 & .03 & 1 & 1.21 & .01 \\
\hline S/I (error) & 23 & $(521,058.60)$ & & 36 & $(409,866.16)$ & & 38 & $(246,851.82)$ & \\
\hline \multicolumn{10}{|c|}{ Within subjects } \\
\hline Trial type (I) & 1 & $4.93^{*}$ & .06 & 1 & 2.62 & .01 & 1 & 0.72 & - \\
\hline$I \times T$ & 1 & 0.05 & - & 1 & 0.72 & - & 1 & 0.38 & - \\
\hline $\mathrm{S} \times \mathrm{D} / \mathrm{DA}$ (error) & 23 & $(326,269.52)$ & & 36 & $(124,790.60)$ & & 38 & $(60,679.47)$ & \\
\hline
\end{tabular}

Note. Values in parentheses represent mean-square errors A dash represents an undefined $\omega^{2}$ when $F<1.0$. $\mathrm{S}=$ participants.

$* p<.05$.

instructions to rehearse do little to improve memory for briefly delayed intentions. Cowan (1999) argued that maintaining focus, particularly in the face of distraction, is an effortful process. Given the heavy demands in our experiment of performing two ongoing tasks while also trying to maintain an intention, a potentially more effective strategy is one that does not necessarily require resources over the delay period.

Gollwitzer (1999) presented impressive data showing that implementation intentions are effective for remembering intended actions in a variety of situations such as taking vitamin supplements (Sheeran \& Orbell, 1999). Implementation intentions involve forming detailed plans in which an intended action is specifically thought of in response to an eliciting cue. For example, instead of forming the general intention "I will take my vitamins," an implementation intention involves forming the specific intention "At the breakfast table each morning, I will take my vitamins." According to Gollwitzer (1999), "once people have formed implementation intentions, goal-directed behavior will be triggered automatically when the specified situation is encountered" ( $p$. 501). In using an implementation intention, one no longer needs to actively maintain an intention over delay because one can rely on an automatic retrieval process that brings the intention to mind when the triggering stimulus occurs (cf. Chasteen et al., 2001; Lengfelder \& Gollwitzer, 2001).

Although existing research suggests that implementation intentions provide substantial benefits in some prospective memory situations, the conditions over which the strategy will be effective are not yet known. For example, participants in past studies have typically been given as much time as needed to form the implementation intention (e.g., Chasteen et al., 2001, allowed 45 s), and the trigger for action was the occurrence of a new environmental condition. It is not clear whether implementation intentions will be effective with more limited encoding time and when the signal to perform an action is the end of a particular task (which seems to often be the case in many real-world work applications, e.g., "I'll get to this after I finish this task"). To evaluate the effectiveness of implementation intentions under these conditions, we compared the prospective memory of a control group with an implementation-intention group in Experiment 3.

In this experiment, the red screen appeared for $6 \mathrm{~s}$ rather than for 2 s. Chasteen et al. (2001), in a study conducted exclusively with older adults, gave participants $45 \mathrm{~s}$ to form an implementation intention and found that they remembered to perform the prospective memory task more often than did control participants. Loukopoulos et al. (2001) observed that pilots have great difficulty focusing on a single task in the cockpit because they are often performing several tasks simultaneously and are frequently interrupted, thus, spending $45 \mathrm{~s}$ on an implementation intention seemed too long to be useful for simulating demanding real-world work settings. On the basis of using a time that could realistically be introduced in work settings along with reactions from participants in pilot work, we decided to give participants $6 \mathrm{~s}$ to form an implementation intention.

As in the second experiment, we also measured the cost of performing a prospective memory task on the speed and accuracy of performing the cover-task activities. Because we assumed that control participants were relying on active maintenance with control instructions, we again expected costs to the cover task. To the extent that implementation-intention participants rely on a relatively automatic retrieval process, there should be no costs to cover-task performance in this condition.

\section{Method}

Design and participants. The design of this experiment was a $2 \times 3$ mixed factorial in which the type of prospective memory instructions (control, implementation intention) was varied between subjects and the length of the delay ( $5 \mathrm{~s}, 15 \mathrm{~s}, 40 \mathrm{~s}$ ) was varied within subjects. Participants were Furman University students who received general psychology course credit for participating. The 48 participants were randomly assigned to two groups, and all were tested individually. Two experimenters tested participants in this experiment, and they were balanced across conditions. When questioned at the end of the experiment, 2 participants indicated confusion with the task, and they were dropped from the analysis and replaced with 2 others.

Procedure and materials. The red screen in this experiment appeared for $6 \mathrm{~s}$ instead of $2 \mathrm{~s}$. Otherwise, except for the implementation intention instructions, the procedure and materials were identical to those used in Experiment 2. As in the first two experiments, control participants were not given a specific strategy. They were simply told that upon seeing a red screen, they should press the slash key but not until there was a change in task. Participants in the implementation intention condition were told to visualize a task change and then to imagine themselves pressing a slash key 
immediately following the change. To help them remember this strategy, the phrase "task change, press slash key" appeared on each red screen.

\section{Results}

Prospective memory. To examine performance on the prospective memory task, we tabulated the proportion of times (out of two) that participants correctly responded on a prospective memory trial for each of the three delays. These proportions, which are shown in Figure 4, were subjected to a $2 \times 3$ mixed ANOVA that included the between-subjects variable of prospective memory instructions (control, implementation intention) and the withinsubjects variable of delay ( $5 \mathrm{~s}, 15 \mathrm{~s}, 40 \mathrm{~s})$. This analysis (shown in Table 8$)$ indicates that implementation-intention instructions $(M=$ .81) did not improve performance beyond that of the control group $(M=.85)$. Our power to detect a medium effect was 39 (the effect size reported in Chasteen et al., 2001). As in the prior experiments, there were no significant changes in performance across the three delay lengths (the power to detect a large effect of the delay variable was .90), and there was no interaction of a large magnitude between delay and prospective memory instructions.

Cover-task performance. As in Experiment 2, we examined the costs of performing a prospective memory task on cover-task performance by comparing the proportion of cover-task items correctly answered on prospective memory and control trials. These proportions were included in a $2 \times 3 \times 2$ mixed ANOVA that contained the between-subjects variable of instructional condition (control, implementation intention) and the within-subjects variables of delay ( $5 \mathrm{~s}, 15 \mathrm{~s}, 40 \mathrm{~s}$ ) and type of trial (control, prospective memory). As can be seen in Table 9, there was a significant effect of type of trial, indicating that participants answered a greater proportion of cover-task items when they were not also performing the prospective memory task $(M=.71$ on nonprospective memory trials, and $M=.62$ on prospective memory trials; see Table 10). As in Experiment 2, this was an effect of small magnitude. There was not a significant effect of delay or of instructional condition, and none of the interactions were significant.

We also examined the cost of maintaining an intention on the speed of performing the cover-task activities. As in Experiment 2, we tabulated response times only for correct responses, and we excluded responses that were more than two standard deviations from the mean. The means are presented in Table 9. The valid responses were used to conduct three (one for each delay interval) $2 \times 2$ mixed ANOVAs with each analysis including the betweensubjects variable of instructional condition (control, implementation intentions) and the within-subjects variable of presence of a prospective memory task (control, prospective memory).

Sixteen control participants and 18 implementation-intention participants had valid scores for the 5-s delay condition. As shown in Table 11, performing a prospective memory task did not significantly slow down processing of the cover-task items. This comparison of the speed of performing the cover-task items with and without a prospective memory task also was not significant in the 15-s delay condition (with 23 control participants and 22 implementation-intention participants) and in the 40-s delay condition (with all 24 participants in each group). Also, as can be seen in Table 11, none of the other effects in these analyses were significant.

Other measures. We tabulated the proportion of digits correctly recalled during the divided-attention trials. These proportions were included in a $2 \times 4$ mixed ANOVA that included the between-subjects variable of type of instruction (control, implementation intention) and type of delay ( $5 \mathrm{~s}, 15 \mathrm{~s}, 40 \mathrm{~s}$, control). On average, participants recalled $82 \%$ of the digits, and this was not significantly affected by the presence of a prospective memory task $(F<1)$ or by the type of instruction $(F<1)$. Also, the interaction between these two variables was not significant, $F(3$, $138)=2.37, M S E=.025, \omega^{2}=.01$.

All participants indicated at the end of the experiment that they had understood the prospective memory instructions. Also, all of

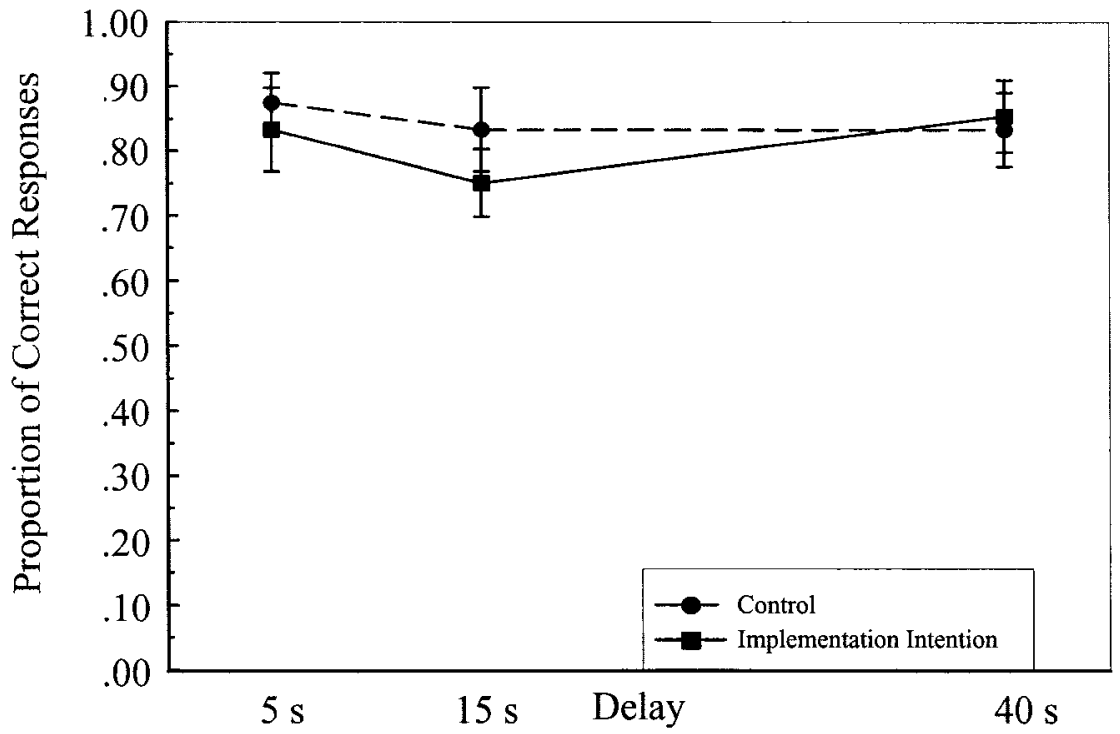

Figure 4. Mean proportion of correct prospective memory responses as a function of delay and instructional condition in Experiment 3 (error bars represent the standard error). 
Table 8

Analysis of Variance for Prospective Memory Scores in Experiment 3

\begin{tabular}{lcc}
\hline \multicolumn{1}{c}{ Source } & $\mathrm{df}$ & $\mathrm{F}$ \\
\hline & Between subjects & \\
Instruction (I) & 1 & 0.56 \\
S/R (error) & 38 & $(.08)$ \\
\hline & Within subjects \\
Delay (D) & 2 & \\
$\mathrm{I} \times \mathrm{D}$ & 2 & 0.68 \\
$\mathrm{~S} \times \mathrm{D} /$ I (error) & 92 & 0.41 \\
\hline
\end{tabular}

Note. Values in parentheses represent mean square errors. Effect sizes were not displayed because all were undefined as a result of $F<1.0 . \mathrm{S}=$ participants.

the participants remembered to perform the prospective memory tasks on at least one of the six memory trials, thereby indicating that forgetting to perform the delayed intention was due to prospective memory, and not retrospective memory, problems.

Participants' ratings of the extent to which they rehearsed during the delay (with 1 representing let it pop into mind and 5 representing rehearsed) revealed no significant difference between the control $(M=3.54)$ and implementation intention $(M=3.83)$ conditions $(F<1)$. On average, participants indicated that they tried to rehearse when maintaining delayed intentions.

\section{Discussion}

When maintaining an intention, there was a significant decrease in the proportion of cover-task items answered correctly. This result is consistent with that of Experiment 2 and demonstrates that people with both control and implementation-intention instructions devote some resources to maintaining the activation of the intention over brief delays. The presence of these costs argues against

Table 9

Analysis of Variance for Cover Items Answered Correctly in Experiment 3

\begin{tabular}{lccc}
\hline \multicolumn{1}{c}{ Source } & $d f$ & $F$ & $\omega^{2}$ \\
\hline \multicolumn{4}{c}{ Between subjects } \\
Instruction (I) & 1 & 0.55 & \\
S/I (error) & 46 & $(.27)$ & \\
\hline \multicolumn{4}{c}{ Within subjects } \\
Delay (D) & 2 & 0.28 & -03 \\
$\mathrm{I} \times \mathrm{D}$ & 2 & 0.48 & - \\
$\mathrm{S} \times \mathrm{D} / \mathrm{I}$ (error) & 92 & $(0.05)$ & -00 \\
Trial type (T) & 1 & $8.89 * *$ & - \\
$\mathrm{I} \times \mathrm{T}$ & 1 & 0.66 & \\
$\mathrm{~S} \times \mathrm{T} / \mathrm{I}$ (error) & 46 & $(0.07)$ & \\
$\mathrm{D} \times \mathrm{T}$ & 2 & 1.54 & \\
$\mathrm{D} \times \mathrm{T} \times \mathrm{I}$ & 2 & 0.10 & \\
$\mathrm{~S} \times \mathrm{D} \times \mathrm{T} / \mathrm{I}$ (error) & 92 & $(0.05)$ & \\
\hline
\end{tabular}

Note. Values in parentheses represent mean square errors. A dash represents an undefined $\omega^{2}$ when $F<1.0 . \mathrm{S}=$ participants.

$* * p<.01$.
Table 10

Accuracy and Speed of Cover-Task Performance as a Function of Instructional Condition, Delay, and Type of Trial in

Experiment 3

\begin{tabular}{llll}
\hline & \multicolumn{3}{c}{ Delay } \\
\cline { 2 - 4 } $\begin{array}{l}\text { Instructional condition } \\
\text { and type of trial }\end{array}$ & $5 \mathrm{~s}$ & $15 \mathrm{~s}$ & $40 \mathrm{~s}$ \\
\hline \multicolumn{2}{c}{ Proportion of category-task items answered correctly } \\
Control & .73 & .66 & .65 \\
$\quad$ Control & .60 & .63 & .60 \\
$\quad \begin{array}{l}\text { Prospective } \\
\text { Implementation intention }\end{array}$ & .77 & .76 & .72 \\
$\quad$ Control & .58 & .66 & .66 \\
Prospective &
\end{tabular}

Speed (in ms) of category-task performance for items answered correctly Control

\begin{tabular}{llll} 
Control & 3,274 & 3,258 & 3,290 \\
Prospective & 3,325 & 3,306 & 3,221 \\
Implementation intention & & & \\
$\quad$ Control & 3,305 & 3,250 & 3,263 \\
Prospective & 3,723 & 3,531 & 3,372 \\
\hline
\end{tabular}

both the minimal demands view and the prohibitively expensive view.

The results also reveal that implementation intentions do not improve prospective remembering under demanding and dynamic conditions such as those used in the present research. Also, contrary to expectations, performing an implementation intention did not reduce costs to cover-task performance relative to control instructions. These results suggest an important limitation to the effectiveness of implementation intentions, and along with the results of Experiment 2 indicate that it is difficult to improve memory for briefly delayed intentions in demanding task settings with cognitive strategies.

\section{General Discussion}

At first blush it appears that maintaining a single intention over delays as brief as $5 \mathrm{~s}$ would pose no difficulty for the human cognitive system. Our results suggest that prospective memory situations introduce special challenges for the functionality of a short-term memory representation. Specifically, the strength of the short-term representation must be higher to support prospective memory relative to retrospective memory.

\section{Theoretical Implications}

Our results do not support either the minimal demands view or the prohibitively expensive view. According to the minimal demands view, it is relatively easy for the cognitive system to maintain a single intention at least for very brief delays. Thus, prospective memory performance should have been high, it should not have been affected by additional demands on attention, and maintaining an intention should have produced no cost to performance of the cover-task activities. None of these predictions was supported. When there is no external agent to prompt retrieval of a briefly held intention (as is the case in prospective memory), successful remembering seems to require maintaining that information at a higher level of activation. 
Table 11

Analyses of Variance for Response Times to Correctly Answered Cover-Task Items in Experiment 3

\begin{tabular}{|c|c|c|c|c|c|c|c|c|c|}
\hline \multirow[b]{2}{*}{ Source } & \multicolumn{3}{|c|}{ 5-s delay } & \multicolumn{3}{|c|}{15 -s delay } & \multicolumn{3}{|c|}{ 40-s delay } \\
\hline & $d f$ & $F$ & $\omega^{2}$ & $d f$ & $F$ & $\omega^{2}$ & $d f$ & $F$ & $\omega^{2}$ \\
\hline \multicolumn{10}{|c|}{ Between subjects } \\
\hline Instruction (I) & 1 & 3.40 & .06 & 1 & 0.56 & - & 1 & 0.41 & - \\
\hline $\mathrm{S} / \mathrm{I}$ (error) & 32 & $(228,981.24)$ & - & 43 & $(477,543.74)$ & - & 46 & $(227,909.20)$ & - \\
\hline \multicolumn{10}{|c|}{ Within subjects } \\
\hline Trial type (I) & 1 & 3.18 & .04 & 1 & 3.87 & .02 & 1 & 0.13 & - \\
\hline $\mathrm{I} \times \mathrm{T}$ & 1 & 1.95 & .02 & 1 & 1.95 & .01 & 1 & 2.63 & .01 \\
\hline $\mathrm{S} \times \mathrm{D} / \mathrm{DA}$ (error) & 32 & $(293,712.75)$ & - & 43 & $(157,039.12)$ & - & 46 & $(73,523.64)$ & - \\
\hline
\end{tabular}

Note. Values in parentheses represent mean square errors. A dash represents an undefined $\omega^{2}$ when $F<1$. S $=$ participants.

According to the prohibitively expensive view, maintaining an intention in working memory requires high levels of resources as would be the case if it required continual maintenance in focal awareness (Cowan, 1999). Under the conditions of this experiment, in which participants were expected to maintain good performance on a demanding cover task (which seems typical of many work settings), the idea is that people cannot expend the resources needed to maintain the intention in working memory. In principle, however, if people were indifferent to performance on the cover task, they should be able to expend the resources needed to maintain the intention. The predictions of the prohibitively expensive view were that there should have been no effects of dividing attention (because participants were not able to maintain the intention in the first place), significant declines in remembering over longer delays, and no cost to the accuracy and speed of performing the cover-task activities. Clearly, these predictions were not borne out. It is interesting to note that our failure across all three experiments to find progressive memory losses over longer delays (despite high power) contrasts with the large forgetting functions typically observed with retrospective memory (Washburn \& Astur, 1998). It should be noted, however, that our longest delay was $40 \mathrm{~s}$, and memory losses might be associated with longer delays.

Instead, the results are consistent with the view that there are moderate resource demands to maintaining an intention over a brief delay, and we speculate that participants attempt to periodically activate the intention over the delay period. Periodic activation would lead to constant performance over the delay interval, as was found in Experiments 1-3. One mechanism that would support periodic activation is an associative relation between the prospective memory intention and the cover activities. This associative relation seems plausible given the contiguity of the cover activities and the retrieval and formation of the intention (i.e., when the red screen occurs) and is consistent with the findings of Nowinski and Dismukes (2003) showing higher prospective memory performance when the cover task at retrieval matched the one that was present during the encoding of the prospective memory instructions. Another mechanism that would support periodic activation is strategic retrieval of the uncompleted intention from long-term memory. The idea here is that people periodically check their memory for uncompleted intentions (cf. Ellis, 1996; Kvavilashvili, 1987). It seems probable that both contextual cuing and periodic checks of memory are more likely during lulls or less-demanding periods in the cover task. The results showing decrements in prospective memory as a result of dividing attention are entirely in line with this reasoning as are the results showing no further decrements in memory performance over longer delays and only small costs to the speed and accuracy of performing the cover activities.

\section{Applied Implications}

These results have several important practical implications. First, they indicate that maintaining intentions over brief delays and then executing them is not a trivial task for the human cognitive system. Our suspicion is that people in general do not realize that retrieved intentions that cannot be performed immediately are quite fragile. Often, retrieved intentions are so salient that they create the misimpression that they are indelible, at least over very brief delays. In work situations for which these kinds of demands are frequent, it seems critical that people are made aware of the frailty of this kind of memory.

A second finding with important applied implications is that interruptions exacerbate the difficulty of successfully maintaining an intended action over a brief delay. As reflected in a small effect size, we found that a 15 -s interruption was disruptive to performance, especially when attention was not divided. McDaniel, Einstein, Graham, and Rall (in press) have replicated this finding in two experiments with interruptions as brief as $10 \mathrm{~s}$. We have suggested that participants, when they encounter delays, periodically activate the intention, either through contextual cuing or strategic checking of uncompleted intentions. One possible explanation of the effects of interruptions is that by virtue of switching participants' attention to a new task, processing of the old task demands (including the prospective memory task) is suspended, and perhaps it is difficult to reactivate the entire set of task demands upon return from the interruption. This could explain the reduced effects of interruptions under divided-attention conditions because the degree of context change with an interruption is more 
extreme in the undivided-attention condition than it is in the divided-attention condition (in which the digit-detection task continues through the interruption). At this point, further research is needed to fully evaluate this view. Edwards and Gronlund (1998) have shown that complex interruptions that are similar to the ongoing task demands can disrupt retrospective memory for the uncompleted intention. Our research indicates that people who work in settings with many interruptions should additionally be warned of their effects on remembering to initiate a delayed intention (i.e., prospective memory).

A third practical issue raised by our findings concerns how one might best solve the challenges of remembering an intention after brief delays. In the retrospective memory literature, there are many examples in which cognitive interventions produce substantial benefits (Bellezza, 1981; Bower, 1970; Pressley, Symons, McDaniel, Snyder, \& Turnure, 1988; Stein et al., 1982). In the prospective memory arena, implementation intentions have been shown to be highly effective in helping people remember to perform intended actions (Chasteen et al., 2001; Gollwitzer, 1999).

In contrast to these findings, our results showing no significant benefits of cognitive strategies suggest that the particular cognitive interventions tested may be ineffective in highly demanding work settings. Our power to detect a medium effect of these strategies was not large, however, thus these initial results should be viewed with caution. Nonetheless, these initial results suggest limitations to the effectiveness of these cognitive strategies in these contexts. The finding that continuous rehearsal instructions did not improve memory in Experiment 2 indicates that it is difficult to maintain an intention in focal awareness while performing demanding cover activities. There appear to be limitations to effective use of the implementation intention strategy as well. In past-research showing beneficial effects of implementation intentions, participants were typically given as much time as needed to form their encoding, and it is not clear that implementation intentions can be effective when people are given only a few seconds to image the associative relation. Another possible problem with using an implementation intention in the current situation is that there was no specific and concrete stimulus that could serve as the trigger for responding. At this point, further research with larger sample sizes and examining other cognitive interventions (e.g., placing high value on not making errors) is needed before strongly concluding that these kinds of strategies are ineffective in highly demanding contexts.

In light of the present findings, however, a more promising approach for improving memory in settings in which the demand for cognitive resources is high may be to develop external signals. Under conditions nearly identical to those of the standard group in Experiment 1, McDaniel, Einstein, Graham, and Rall (in press) found that presenting a small blue dot in the lower right-hand corner of the computer screen enabled participants to completely overcome the negative effects of interruptions. Thus, in situations in which it is critical not to forget delayed intentions, human factors engineers may want to consider designing a general external prospective memory light into the operator's display.

In summary, our research shows that when busily engaged in activities, it is difficult for the cognitive system to maintain delayed intentions in focal awareness even for $5 \mathrm{~s}$. When considered in relation to typical levels of retrospective memory performance, the forgetting rates in our experiments (around 8\% in the standard condition, $20-25 \%$ in the demanding conditions, and $30-40 \%$ when interruptions occurred) are not large. They are too high, however, when considered in the context of critical work settings (such as the aviation examples described in the introduction) where forgetting only occasionally can have catastrophic consequences.

\section{References}

Baddeley, A. (1986). Working memory. New York: Oxford University Press.

Baddeley, A., \& Hitch, G. (1974). Working memory. In G. H. Bower (Ed.), The psychology of learning and motivation (Vol. 8, pp. 47-89). New York: Academic Press.

Bellezza, F. (1981). Mnemonic devices: Classification, characteristics, and criteria. Review of Educational Research, 51, 247-275.

Bower, G. (1970). Analysis of a mnemonic device. American Scientist, 58 , 496-510.

Brown, J. (1958). Some tests of the decay theory of immediate memory. Quarterly Journal of Experimental Psychology, 10, 12-21.

Butterfield, E. C. (1964). The interruption of task: Methodological, factual, and theoretical issues. Psychological Bulletin, 62, 309-322.

Camp, C. J., Foss, J. W., Stevens, A. B., \& O'Hanlon, A. M. (1996). Improving prospective memory task performance in persons with Alzheimer's disease. In M. Brandimonte G. O. Einstein, \& M. A. McDaniel (Eds.), Prospective memory: Theory and applications (pp. 351-368). Mahwah, NJ: Erlbaum.

Chasteen, A. L., Park, D. C., \& Schwarz, N. (2001). Implementation intentions and facilitation of prospective memory. Psychological Science, 12, 457-461.

Cohen, J. (1988). Statistical power analysis for the behavioral sciences (2nd ed.). Hillsdale, NJ: Erlbaum.

Cowan, N. (1999). An embedded-process model of working memory. In A. Miyake \& P. Shah (Eds.), Models of working memory: Mechanisms of active maintenance and executive control (pp. 62-101). Cambridge, United Kingdom: Cambridge University Press.

Craik, F. I. M., Govoni, R., Naveh-Benjamin, M., \& Anderson, N. D. (1996). The effects of divided attention on encoding and retrieval processes in human memory. Journal of Experimental Psychology: General, 125, 159-180.

Dismukes, R. K., Young, G., \& Sumwalt, S. (1998). Cockpit interruptions and distractions: Effective management requires a careful balancing act. ASRS Directline, 10, 3.

Edwards, M., \& Gronlund, S. (1998). Task interruption and its effects on memory. Memory, 6, 665-687.

Einstein, G. O., Holland, L. J., McDaniel, M. A., \& Guynn, M. J. (1992). Age-related deficits in prospective memory: The influence of task complexity. Psychology and Aging, 7, 471-478.

Einstein, G. O., \& McDaniel, M. A. (1990). Normal aging and prospective memory. Journal of Experimental Psychology: Learning, Memory, and Cognition, 16, 717-726.

Einstein, G. O., \& McDaniel, M. A. (1996). Retrieval processes in prospective memory: Theoretical approaches and some new empirical findings. In M. Brandimonte, G. O. Einstein, \& M. A. McDaniel (Eds.), Prospective memory: Theory and applications (pp. 115-141). Mahwah, NJ: Erlbaum.

Einstein, G. O., McDaniel, M. A., Manzi, M., Cochran, B., \& Baker, M. (2000). Prospective memory and aging: Forgetting intentions over short delays. Psychology and Aging, 15, 671-683.

Einstein, G. O., Smith, R. E., McDaniel, M. A., \& Shaw, P. (1997). Aging and prospective memory: The influence of increased task demands at encoding and retrieval. Psychology and Aging, 12, 479-488.

Ellis, J. (1996). Prospective memory or the realization of delayed intentions: A conceptual framework for research. In M. Brandimonte, G. O. 
Einstein, \& M. A. McDaniel (Eds.), Prospective memory: Theory and applications (pp. 1-22). Mahwah, NJ: Erlbaum.

Engle, R. W., Tuholski, S. W., Laughlin, J. E., \& Conway, A. R. A. (1999). Working memory, short-term memory, and general fluid intelligence: A latent-variable approach. Journal of Experimental Psychology: General, 128, 309-331.

Faul, F., \& Erdfelder, E. (1992). GPOWER: A priori, post-hoc, and compromise power analyses for MS-DOS [Computer software]. Unpublished manuscript, Bonn University, Bonn, Germany.

Gollwitzer, P. (1999). Implementation intentions: Strong effects of simple plans. American Psychologist, 54, 493-503.

Goschke, T., \& Kuhl, J. (1993). Representation of intentions: Persisting activation in memory. Journal of Experimental Psychology: Learning, Memory, and Cognition. 19, 1211-1226.

Guynn, M. J. (2002). Footprints of monitoring in event-based prospective memory. Manuscript submitted for publication.

Hicks, J. L., Marsh, R. L., \& Russell, E. J. (2000). The properties of retention intervals and their affect on retaining prospective memories. Journal of Experimental Psychology: Learning, Memory, and Cognition, 26, 1160-1169.

Keppel, G., \& Underwood, B. J. (1962). Proactive inhibition in short-term retention of single items. Journal of Verbal Learning and Verbal Behavior, 1, 153-161.

Kvavilashvili, L. (1987). Remembering intention as a distinct form of memory. British Journal of Psychology, 78, 507-518.

Lengfelder, A., \& Gollwitzer, P. (2001). Reflective and reflexive action control in patients with frontal brain lesions. Neuropsychology, 15, $80-100$.

Loukopoulos, L. D., Dismukes, R. K., \& Barshi, I. (2001). Cockpit interruptions and distractions: A line observation study. In R. Jensen (Ed.), Proceedings of the 11th International Symposium on Aviation Psychology, Columbus: Ohio State University.

Mäntylä, T. (1996). Activating actions and interrupting intentions: Mechanisms of retrieval sensitization in prospective memory. In M. Brandimonte, G. O. Einstein, \& M. A. McDaniel (Eds.), Prospective memory: Theory and applications (pp. 93-113). Mahwah, NJ: Erlbaum

Marsh, R. L., \& Hicks, J. L., (1998). Event-based prospective memory and executive control of working memory. Journal of Experimental Psychology: Learning, Memory, and Cognition, 24, 336-349.

Marsh, R. L., Hicks, J. L., \& Bink, M. L. (1998). Activation of completed, uncompleted, and partially completed intentions. Journal of Experimental Psychology: Learning, Memory, and Cognition, 24, 350-361.

Maxwell, S. E., \& Delaney, H. D. (2004). Designing experiments and analyzing data (2nd ed.). Mahwah, NJ: Erlbaum.

McDaniel, M. A., \& Einstein, G. O. (2000). Strategic and automatic processes in prospective memory retrieval: A multiprocess framework. Applied Cognitive Psychology, 14, S127-S144.

McDaniel, M. A., Einstein, G. O., Graham, T., \& Rall, E. (in press). Delaying execution of intentions: Overcoming the costs of interruptions. Applied Cognitive Psychology.

McDaniel, M. A., Einstein, G. O., Stout, A., \& Morgan, Z. (in press). Aging and maintaining intentions over delays: Do it or lose it. Psychology and Aging.

McDaniel, M. A., Robinson-Riegler, B., \& Einstein, G. O. (1998). Prospective remembering: Perceptually-driven or conceptually-driven processes? Memory \& Cognition, 26, 121-134.

Monk, C. A., Boehm-Davis, D. A., \& Trafton, J. G. (2002). The attentional costs of interrupting task performance at various stages. Proceedings of the Human Factors and Ergonomics Society Annual Meeting (pp. 18241828). Santa Monica: Human Factors and Ergonomics Society.

Muter, P. (1980). Very rapid forgetting. Memory and Cognition, 8, 174179 .
Navon, D., \& Gopher, D. (1979). On the economy of the human processing system. Psychological Review, 86, 214-255.

Norman, D. A., \& Bobrow, D. (1975). On data limited and resource-limited processes. Cognitive Psychology, 7, 44-64.

Nowinski, J. L., \& Dismukes, R. K. (2003). Effects of ongoing task context and target typicality on prospective memory performance: The importance of associative cuing. Manuscript submitted for publication.

Nowinski, J. L., Holbrook, J. B., \& Dismukes, R. K. (2003). Human memory and cockpit operations: An ASRS study. In Proceedings of the 12th International Symposium on Aviation Psychology (pp. 888-893). Dayton, OH: The Wright State University.

Peterson, L. R., \& Peterson, M.J. (1959). Short-term retention of individual verbal items. Journal of Experimental Psychology, 58, 193-198.

Pressley, M., Symons, S., McDaniel, M. A., Snyder, B. L., \& Turnure, J. E. (1988). Elaborative interrogation facilitates acquisition of confusing facts. Journal of Educational Psychology, 80, 457-464

Ratcliff, R. (1979). Group reaction time distributions and an analysis of distribution statistics. Psychological Bulletin, 86, 446-461.

Reason, J. (1990). Human error. Cambridge, England: Cambridge University Press.

Reitman, J. S. (1974). Without surreptitious rehearsal, information in short-term memory decays. Journal of Verbal Learning and Verbal Behavior, 13, 365-377.

Salthouse, T. A., \& Babcock, R. L. (1991). Decomposing adult age differences in working memory. Developmental Psychology, 27, 763776 .

Salthouse, T. A., Hambrick, D. Z., Lukas, K. E., \& Dell, T. C. (1996). Determinants of adult age differences on synthetic work performance. Journal of Experimental Psychology: Applied, 2, 305-329.

Schweickert, R., \& Boruff, B. (1986). Short-term memory capacity: Magic number or magic spell? Journal of Experimental Psychology: Learning, Memory, and Cognition, 12, 419-425.

Sheeran, P., \& Orbell, S. (1999). Implementation intentions and repeated behaviors: Augmenting the predictive validity of the theory of planned behavior. European Journal of Social Psychology, 29, 349-370.

Smith, R. E. (2003). Conscious capacity and prospective memory: A new perspective. Journal of Experimental Psychology: Learning, Memory, and Cognition, 29, 347-361.

Stein, B. S., Bransford, J. D., Franks, J. J., Owings, R. A., Vye, N. J., \& McGraw, W. (1982). Differences in the precision of self-generated elaborations. Journal of Experimental Psychology: General, 111, 399_ 405 .

Stone, M., Dismukes, R. K., \& Remington, R. (2001). Prospective memory in dynamic environments: Effects of load, delay, and phonological rehearsal. Memory, 9, 165- 176.

Turner, M. L., \& Engle, R. W. (1989). Is working memory task dependent? Journal of Memory and Language, 28, 127-154.

Vortac, O. U., Edwards, M., \& Manning, C. A. (1995). Functions of external cues in prospective memory. Memory, 3, 201-219.

Washburn, D., \& Astur, R. S. (1998). Nonverbal working memory of humans and monkeys: Rehearsal in the sketchpad? Memory \& Cognition, 26, 277-286.

Waters, G. S., \& Caplan, D. (1996). The measurement of verbal working memory capacity and its relation to reading comprehension. Quarterly Journal of Experimental Psychology: Human Experimental Psychology, 49 (A), 51-79.

Wickens, C. D. (2002). Situation awareness and workload in aviation Current Directions in Psychological Science, 11, 128-133.

Received August 20, 2001

Revision received April 22, 2003

Accepted April 25, 2003 